\title{
Las teorías conspirativas, ¿un rasgo de la cultura de nuestro tiempo? Reseña de Michael Barkun, A Culture of Conspiracy. Apocalyptic Visions in Contemporary America. Berkeley, University of California Press, 2013, 306 págs.
}

Entre los numerosos comportamientos políticos y sociales que ha sacado a la luz la presente pandemia del Covid-19 hay uno que acaso haya pasado desapercibido a la mayoría de la población porque forma parte de la inextinguible lluvia de informaciones que la acompañan. Pero es un tema que reviste gran importancia para politólogos, historiadores del presente y especialistas en estudios culturales. Me refiero a la cultura de la conspiración, a la creencia de que poderes o grupos ocultos vienen trabajando sin descanso a lo largo de la historia, pero sobre todo en el siglo XX y en tiempos recientes, para destruir los cimientos de las sociedades, los países, el propio orden político internacional e incluso implantar una suerte de tiranía de dimensiones globales. Así, estos días pasados hemos leído noticias tales como la de que la televisión estatal rusa atribuía el origen de la epidemia a una maniobra desestabilizadora de Estados Unidos dirigida contra la economía china, o que el propio presidente Donald Trump no dudaba en acusar a este último país de la estrategia opuesta.

En realidad, la cultura de la conspiración no es un fenómeno aislado e intrascendente, sino que forma parte, y cada vez con más ubicuidad, de los referentes o comportamientos políticos en la sociedad global y el orden internacional posterior a la Guerra Fría. Hay autores que identifican incluso el auge de esta clase de relatos con el ascenso de los populismos; como hacen, por ejemplo, Ivan Krastev y Stephen Holmes en su reciente La luz que se apaga. Cómo Occidente ganó la Guerra Fría, pero perdió la paz (2019), del que el lector puede hallar una excelente versión en español en la Editorial Debate.

El libro que traemos para reseñar, A Culture of Conspiracy. Apocalyptic Visions in Contemporary America, pese a su publicación en 2013, merece la pena ser rescatado y darse a conocer al estudioso de ámbito hispano, porque es probablemente el trabajo más acabado sobre el fenómeno. Su autor, Michael Barkun, profesor emérito de Ciencia Política de la Universidad de Syracuse en Estados Unidos, viene acreditando desde hace varias décadas investigaciones sobre movimientos milenaristas, violencia religiosa y grupos racistas de los Estados Unidos.

En realidad, como adelanta este en las primeras páginas, estamos ante una obra preparada en los años 1990, publicada por primera vez a las pocas semanas del 11-S, pero que, a la vista de las consecuencias de tal acontecimiento, fue necesario rehacer con numerosos cambios a lo largo del decenio siguiente. El resultado final es un estudio de historia cultural sugerente y denso, que llega hasta acontecimientos y publicaciones que tuvieron lugar o vieron la luz en 2012.

Para una revista como Historiografías el tema tiene un interés especial, porque, según muestra el propio Barkun, las teorías conspirativas o lo conspiranoico suelen venir acompañados de miradas al pasado remoto y reciente. Además, en los últimos tiempos, el asunto aparece asociado a un género periodístico que afecta a los estudios sobre la historia del siglo XX, y forma parte en cierto modo de esa cultura de la conspiración, 
como es el interés por las llamadas "operaciones de falsa bandera". Se trata este de un tema de limites indefinidos, donde la realidad se entremezcla con la ficción, que se aprovecha del secretismo o de la dificultad de acceso a archivos oficiales que suele aquejar a los estudios sobre la historia del mundo actual, y que persigue reinterpretar o dar un giro de ciento ochenta grados al significado de determinados acontecimientos. Estos pasan a ser, según esos autores, maniobras ocultas de los gobiernos, quienes se valen de sus servicios de inteligencia en la consecución de objetivos inconfesables. Así, por ejemplo, hechos históricos como el ataque japonés a Pearl Harbor, la llamada Operación Gladio - a la que se atribuye la comisión de atentados terroristas en Occidente entre los años 1950 y 1970-, o el propio 11-S, según esta clase de teorías habrían sido provocados o inducidos, en realidad, por el propio gobierno norteamericano a través de sus servicios secretos. También las interpretaciones de la Transición española se han visto influidas por visiones conspirativas en tiempos recientes, como el presentar el 23-F a modo de "golpe institucional" provocado por los servicios secretos y supervisado por las altas instituciones del Estado español y por la CIA norteamericana; o el rescatar la vieja teoría de que la contaminación por aceite de colza, el llamado "síndrome del aceite tóxico" que se produjo unos meses más tarde en la España de 1981, vino en realidad de un escape bacteriológico de la base de Torrejón de Ardoz que fue ocultado por el Estado con ayuda igualmente de la agencia estadounidense.

El libro de Barkun cubre un tema mucho más amplio como es el de las raíces, los aspectos formales, conceptuales incluso, y el porqué del actual auge de las interpretaciones de la política y de lo histórico en clave de conspiración. El libro se centra en los Estados Unidos, un país que, como puso de manifiesto el conocido historiador y politólogo Richard Hofstadter en un libro pionero, se he revelado especialmente proclive a esa clase de cultura; al menos en el último medio siglo.

En A Culture of Conspiracy, la obra pionera de Hofstadter, The Paranoid Style in American Politics and Other Essays (publicada en 1965 y escrita al calor de las primeras teorías sobre el asesinato del presidente John F. Kennedy), también resulta un obligado punto de partida. Sin embargo, los 14 capítulos de A Culture of Conspiracy plantean la interesante hipótesis de que es precisamente en los tres últimos decenios cuando esa clase de visiones han cobrado una fuerza y divulgación inusitadas. La combinación de factores tales como el desarrollo de las industrias de la cultura y la difusión de la cultura popular -y un componentes de esta, las leyendas urbanas-, gracias a las tecnologías de la información y de la comunicación -la red especialmente-, la erosión de la autoridad del gobierno federal en las últimas décadas, e incluso la propia ambigüedad de la idea de "Nuevo orden mundial", que parece haberse colocado en el lugar del enemigo tradicional de los años de la Guerra Fría, el comunismo (infra.), todos son, sostiene el autor de $A$ Culture of Conspiracy, componentes propiciadores del desarrollo de esta clase de cultura. El tema enseguida se ve que no se limita o afecta solo a los Estados Unidos. Pero vayamos por partes.

Los capítulos 1 y 2 del libro resultan especialmente valiosos porque en ellos se concentra y explica todo el aparato conceptual que se va a aplicar en el resto de la obra. A la pregunta inicial de en qué consiste una teoría conspirativa, Barkun responde que se trata de aquella opinión que defiende la existencia de una organización de individuos o de grupos que actúan de manera encubierta para lograr algún fin malévolo u oprobioso implantar una dictadura, controlar o engañar a los ciudadanos, etc.--, pero una creencia 
que se hace acompañar de un relato en el que aparecen estos tres supuestos: a) nada ocurre por accidente; b) nada es lo que aparenta; y c) todo está conectado con todo.

A la pregunta de a qué clase de conocimiento pertenecen las teorías de la conspiración, Barkun da una respuesta no menos interesante y también original, y las incluye en lo que llama el "conocimiento estigmatizado". Es este, señala el autor, un dominio que se presenta a sí mismo como un ámbito proscrito, una víctima de los conocimientos y saberes académicos y/o habitualmente aceptados, en los que se supone que alguien tiene interés en que ese ámbito quede oculto a la opinión pública, marginado u olvidado. No se trata de un fenómeno reciente. Pero factores como los antes citados, esto es, el desarrollo de la cultura popular, las industrias de la cultura -con su capacidad para desdibujar la diferencia entre la realidad y la ficción-, la propia red, etc., han provocado un fenómeno que sin duda también ha contribuido a la mutación y difusión de ese conocimiento estigmatizado: la actual existencia de cierto difuminado de las fronteras entre los saberes habitualmente reconocidos y esa clase de conocimiento.

En realidad, este es un dato digno de subrayarse porque el conocimiento estigmatizado no renuncia en absoluto a la imitación de los procedimientos y aspectos formales de la erudición al uso o a la reivindicación de lo empírico. Esto último, por ejemplo, juega un papel importante en las teorías conspirativas, aunque tampoco eso quiere decir que estas estén sujetas a lo que habitualmente se entiende por falsabilidad, esto es, a la posibilidad de verse refutadas por determinadas pruebas. Al contrario, puesto que esas teorías se las puede considerar sistemas cerrados basados en la sospecha, cualquier prueba en su contra es vista como una estratagema o argucia para desacreditarlas. En ese sentido, como dice el autor, en el conocimiento estigmatizado la principal prueba de verdad es la propia sensación de estigmatización.

En los capítulos 3 a 14 del libro el lector encontrará un minucioso repaso por las teorías y temas de lo conspiranoico en la cultura norteamericana de las últimas décadas, con referencias a textos y autores que se remontan al siglo XIX. No le resultará difícil relacionar algunos de sus datos y análisis con informaciones y teorías que circulan hoy por la red y los medios de comunicación e incluso rondan o afectan de algún modo al ámbito académico.

En esos capítulos se puede observar con toda clase de detalles un quinto rasgo de ese conocimiento estigmatizado (el primero es su victimismo; el segundo, su reciente capacidad para permearse con otros conocimientos; el tercero su imitación de la erudición, y el cuarto su carencia de falsabilidad). Este quinto rasgo es el carácter ilimitado e incluso informe que ha llegado a adquirir en los últimos tiempos. El conocimiento estigmatizado, y las teorías conspirativas más en concreto, pueden incluir las referencias más variopintas que quepa imaginar: desde la alquimia, la astrología, el esoterismo y la medicina natural, hasta sociedades secretas, organizaciones internacionales, gobiernos e incluso supuestas presencias de seres de otros mundos.

Para entender esta tendencia al "collage", que se hace patente en las últimas décadas, el autor ha planteado, también en los dos primeros capítulos, una segunda hipótesis además de la del conocimiento estigmatizado: lo que llama "el milenarismo de estilo improvisado", esto es, la aparición reciente de teorías apocalípticas y/o teleologías que, a diferencia de las de carácter religioso o de las ideologías, digamos laicas, nacidas en el siglo XIX, se nutren de toda clase de elementos. O como dice el autor, visiones que 
pueden combinar ingredientes tan dispares como tradiciones religiosas, ideas sobre la existencia de "una nueva edad", ocultismo, ciencia, radicalismo político tanto de derecha como de izquierda, etc., y abarcar toda clase de fenómenos (espirituales, científicos, políticos, etc.). Debe insistirse de nuevo en que esas teorías apocalípticas han cobrado una especial fuerza tras el final de la Guerra Fría, cuando han quedado asociadas a la idea de "Nuevo orden mundial", expresión que fue difundida por los mandatarios George H. W. Bush y Mijaíl Gorbachov para referirse a la cooperación de las superpotencias, pero lo suficientemente ambigua con su referencia a "una nueva época" como para que puedan caber en ella los componentes más dispares e incluso más disparatados.

En el repaso por autores y obras de los capítulos 3 a 14 de A Culture of Conspiracy, también se observa que los componentes más "clásicos" de las teorías conspirativas, en tanto conocimiento estigmatizado, se remontan a un periodo que va desde comienzos del XIX hasta mediados del XX (los Iluminati, la masonería, "la conspiración judía", el esoterismo, etc.). Pero en ese largo periodo tales ingredientes aparecen generalmente separados entre sí, desconectados, aislados. Solo desde el decenio de 1990 y gracias a su asociación a la idea de Nuevo orden mundial y a los medios de difusión actuales, y a la red por supuesto, ha podido propagarse un "collage" como el que el autor estudia con numerosos ejemplos, que hubiera sido impensable unas décadas antes.

En los capítulos 3 y 4 el lector hallará un examen de los componentes y relatos de lo que llama "las teorías del Nuevo orden mundial". Estos elementos tienen una historia secular de obras y autores en los que ya se apela a asuntos tales como "la llegada del Anticristo" o se menciona a los "Iluminati", pero la década de 1990 lo que hace es actualizarlos, esto es, asociarlos a organizaciones más visibles, que son presentadas como sus instrumentos dirigidos a imponer una tiranía mundial; de modo que la mentada conspiración llega a adquirir incluso un carácter "oximorónico" en el que los más elementales conocimientos de la historia del siglo XX se ponen en duda o sencillamente saltan por los aires -por ejemplo, el que haya existido un enfrentamiento entre el Este y el Oeste o que la Guerra Fría haya sido un fenómeno real-. La lista de esas organizaciones incluye a las Naciones Unidas, "el club Bilderberg", la Comisión Trilateral, el Opus Dei, el Club de Roma, el Foro Económico Mundial, el Vaticano, etc. ¿Sus manifestaciones en suelo norteamericano según estos relatos?: presencia, por ejemplo, de "helicópteros negros", supuestos campos de concentración secretos, procedimientos para el control de la mente de los ciudadanos por parte de ciertas agencias del gobierno, etc.

Los capítulos 5 a 9 examinan con detenimiento un componente que hoy no puede faltar en las teorías conspirativas o relatos más acabados o ambiciosos: el factor "platillos volantes" y "habitantes de otros mundos".

Como materia de opinión pública, en Estados Unidos esta idea nace -señala el autor- después de la Segunda Guerra Mundial (lo inaugura el llamado "Caso Roswell" ocurrido en el verano de 1947 en el estado de Nuevo México, accidente de un globo meteorológico al que la prensa coetánea ya se refirió como "la captura de un platillo volante"). Desde esa época la llamada "ufología" se va a dotar de un "programa político" en el cual uno de sus puntos clave consistirá en afirmar que el gobierno está ocultando el tema a los ciudadanos. Pero, desde finales de los años 1980 el asunto comienza a difundirse ligado a una visión política mucho más amplia. En ella ya no se acusa al gobierno únicamente de negar el fenómeno, sino que incluso se lo coloca detrás de un complot con organizaciones "extranjeras" e incluso con aquellos mismos seres: el tema 
aparece vinculado a una serie de lugares o leyendas urbanas tales como "los hombres de negro", la llamada "Área 51" (estado de Nevada), "los reptilianos", y, sobre todo, a elementos de las teorías conspirativas del Nuevo orden mundial en las que pueden aparecer o reaparecer los Iluminati, los judíos, los gobiernos y/o cualquiera de las antes citadas organizaciones. El objetivo que se denuncia siempre es el mismo: una suerte de “megaconspiración” para implantar una dictadura de dimensiones mundiales.

Los capítulos 10 y 11 llevarán al estudioso a la cultura conspiranoica surgida al calor de 11-S. En ella lo más destacable consiste en cómo esa clase de teorías se han desarrollado con suma rapidez ayudadas indirectamente por la ambiguiedad de los medios de comunicación y las demoras a la hora de emprender una investigación oficial, que no se inició hasta las postrimerías de 2002). Bajo tal clima enseguida han proliferado toda clase de elucubraciones y leyendas urbanas cuyo único punto en común es, precisamente, el negar que el 11-S haya sido un atentado de la organización yihadista Al-Qaeda en territorio estadounidense. El catálogo de referencias en clave conspiranoica incluye "la llegada del Anticristo", las profecías de Nostradamus, los Iluminati, el propio gobierno norteamericano como principal instigador, etc.

Los capítulos 12 y 14 son otra prueba fehaciente de cómo el conocimiento estigmatizado es capaz de albergar collages que alcanzan en años recientes proporciones inusitadas: leyendas urbanas y teorías conspiranoicas en torno al presidente Barack Obama (2009-2016), que van desde negar su nacionalidad estadounidense hasta considerarlo un "caballo de Troya" del ese Nuevo orden mundial, expectativas apocalípticas al hilo del año 2012, que abarcan desde supuestas -y completamente falsaspredicciones del calendario de los Mayas hasta elucubraciones sobre los juegos Olímpicos de Londres, etc.

Ponemos fin a esta reseña recomendando con vehemencia el libro que la ha originado. A Culture of Conspiracy es un sugerente y bien informado estudio de historia cultural que ha sabido ver de qué modo y porqué las teorías conspirativas se vienen convirtiendo en un rasgo de la cultura de nuestro tiempo.

Gonzalo Pasamar Alzuria

Universidad de Zaragoza

gpasamar@unizar.es

Fecha de recepción: 15 de junio de 2020

Fecha de aceptación: 18 de junio de 2020

Publicación: 1 de julio de 2020

Para citar este artículo: Gonzalo Pasamar, "Las teorías conspirativas, ¿un rasgo de la cultura de nuestro tiempo? Reseña de Michael Barkun, A Culture of Conspiracy. Apocalyptic Visions in Contemporary America. Berkeley, University of California Press, 2013, 306 págs.", Historiografías, 19 (enero-junio 2020), pp. 157-161. 